\title{
Assessment of drought trends in the Senegal River Basin by a terrestrial water storage index (GRACE)
}

\author{
Cheikh Faye \\ Department of Geography, UFR Sciences and Technologies, Assane SECK University of Ziguinchor, \\ Laboratory of Geomatics and Environment, BP 523 Ziguinchor, Senegal; \\ cheikh.faye@univ-zig.sn
}

Received: 21 November 2021; Revised: 20 January 2022; Accepted: 24 January 2022;

Published online 31 January 2022

\begin{abstract}
Droughts lead to significant environmental and economic consequences, especially in arid and semi-arid areas like the Sahel. While site-level assessments of drought in the Sahel are abundant, assessments at the scale of entire hydrological basins are less common. Here, we use a new drought index called the terrestrial water storage index (TWSI) to assess trends in drought throughout the Senegal River Basin. This area covers parts of Guinea, Mali, Senegal, and Mauritania, the study period is between 2003 and 2020. Over the entire period, water storage in the Senegal River Basin is increasing by $0.87 \mathrm{~km}^{3} \mathrm{y}^{-1}$ on the total area of the basin. However, we observed two distinct phases within the time period: an overall water deficit between 2003 and 2012 and a surplus between 2013 and 2020. We also found variations in terrestrial water storage from highly negative at the end of the dry season $(-12.47 \mathrm{~cm}$ in May 2003) to strongly positive at the end of the rainy season $(15.30 \mathrm{~cm}$ in September 2020$)$. Our study suggests that the TWSI can be a useful index for regional hydrological drought monitoring, especially for areas where meteo-hydrological observations are insufficient.
\end{abstract}

Key words: terrestrial water storage, GRACE, drought index, groundwater resources, Senegal River Basin

Citation: Faye, C. (2022). Assessment of drought trends in the Senegal River Basin by a terrestrial water storage index (GRACE). Central European Journal of Geography and Sustainable Development, 4(1), 5-22. https://doi.org/10.47246/CEJGSD.2022.4.1.1

https://doi.org/10.47246/CEJGSD.2022.4.1.1

| Full text | 